\title{
HIV in the Filipino Healthcare Worker: A Way Forward
}

\author{
Edsel Maurice Tanghal Salvana ${ }^{1,2}$ and Rontgene M. Solante ${ }^{3,4}$ \\ ${ }^{1}$ Institute of Molecular Biology and Biotechnology, National Institutes of Health, University of the Philippines Manila \\ ${ }^{2}$ Section of Infectious Diseases, Department of Medicine, College of Medicine and Philippine General Hospital, University of the Philippines Manila \\ ${ }^{3}$ San Lazaro Hospital, Department of Health \\ ${ }^{4}$ Department of Medicine, Medical Center Manila
}

\begin{abstract}
The unprecedented increase in HIV cases in the Philippines has not spared healthcare workers. Due to the severe stigma associated with this disease, healthcare workers (HCWs) with HIV face significant discrimination especially if they elect to continue practicing medicine. This article examines the evidence for occupational transmission of HIV from healthcare workers to patients, and provides a framework for ethical testing of HCWs and a means to continue practice while preserving patient safety.
\end{abstract}

Key Words: HIV/AIDS, healthcare workers, Philippines, occupational health

A diagnosis of HIV infection is one of the most devastating events for a person in his lifetime. A diagnosis of HIV is doubly crushing for a health care worker. A healthcare worker (HCW) does not only have to worry about his own health, but needs to know whether he can continue practicing his chosen profession. As the HIV epidemic works its way through the Filipino population, an increasing number of doctors, nurses, and other HCWs find themselves infected with the virus. ${ }^{1}$ The question then arises whether safety can be assured if these HCWs living with HIV continue to care for patients.

Due to the severe stigma associated with HIV in the Philippines, an emotional and even hysterical response has historically predominated. ${ }^{2}$ Reports of HIV-positive medical students being asked to leave medical school, or declare for a non-clinical specialty are common, and do not take into account the actual risk to patients and the inherent human rights of these HCWs to practice their profession.

Advances in antiretroviral treatment and our understanding of viral transmission dynamics has shown a way forward. In 2010, the Society for Healthcare Epidemiology of America released a document for the HCW

Corresponding author: Edsel Maurice T. Salvana, MD, DTM\&H, FIDSA Institute of Molecular Biology and Biotechnology

National Institutes of Health

University of the Philippines Manila

625 Pedro Gil St. Ermita, Manila 1000 Philippines

Telephone: +6325251062

Email: edsel.salvana@gmail.com infected with a blood-borne pathogen. ${ }^{3}$ It included guidance for hepatitis B, hepatitis C and HIV. For the purposes of this review, we will only tackle the applicability of these guidelines for HIV to the Philippine setting. In addition, the United Kingdom recently rescinded its ban on HIV-infected physicians performing exposure-prone procedures last April 2014 as a result of extensive consultations with experts and HCWs. ${ }^{4}$ In response to this announcement, Australia has circulated a draft of an update to its guidelines seeking to lift their own ban and move forward with a framework for patient safety. ${ }^{5}$

\section{Rationale for the approach}

While most physicians and other HCWs are generally looked up to by society as highly ethical and beneficent human beings, the high stakes involved when an HCW is diagnosed with HIV can preclude adequate testing behavior despite the presence of risk factors. Moreover, even if a diagnosis is made, the strict confidentiality laws of the Philippines (Republic Act 8504) that are meant to protect the privacy of individuals can serve as a shield for the HCW to not disclose his or her status to hospital authorities due to fear of curtailment of privileges and outright expulsion. The privilege to practice medicine is a hard-won goal of a lifetime, and the fear of losing one's livelihood and vocation can lead to nondisclosure, which in the long run puts patients at a much higher risk for infection. The benefits of adequate HIV testing for HCWs are three-fold: it ensures early intervention with antiretrovirals which can restore life expectancy of the HCW if given early; it lowers the risk of transmitting HIV to a patient; and it allows the HCW to continue practicing medicine in a reasonably safe manner. ${ }^{3,6-8}$ The argument to just mandatorily test all HCWs for HIV prior to allowing them practice is not only illegal, it is inherently discriminatory, and can lead to high-risk HCWs into going underground or deceiving the system, which in the end will compromise patient safety. Rather, with the assumption that HCWs are beneficent persons, the impetus should be that all HCWs who practice medicine and have risk factors for HIV, whether through sexual or occupational exposure, are ethically obligated to know their HIV status, since the crux of the privilege to practice medicine is to improve, and not to further compromise, a patient's health. ${ }^{3}$ 
To allay the fear of removal of practice privileges, it is hoped that a framework in which HCWs can continue to practice safely despite an HIV diagnosis will provide the impetus to automatically and voluntarily test for HIV, however often it is necessary.

\section{Risks involved}

Exposure risks have been traditionally divided into three categories: Category I - de minimis or no risk procedures; Category II - low risk but transmission is not impossible, and Category III - there is documented evidence of transmission, also known as exposure prone procedures. ${ }^{3}$ The reader is referred to the most recent SHEA guidelines, available free full text online at http://www.sheaonline.org/Assets/files/guidelines/BBPathogen_GL.pdf for the specific procedures under each category. ${ }^{3}$ In general, Category I procedures include routine history and physical, minor surface suturing, non-emergency peripheral venoclysis, rectal and vaginal exams, and lower gastrointestinal endoscopy. Examples of Category II procedures include upper gastrointestinal endoscopy, bronchoscopy, minor local procedures (incision and drainage of abscess, minor biopsies with local anesthesia), minor gynecological procedures (dilatation and curettage, colposcopy, insertion and removal of contraceptive devices, collecting ova), epidural and spinal anesthesia, minor vascular procedures, amputations, cardiac catheterization, subcutaneous pacemaker insertion, and minor plastic surgery, among others. The physician's hands should always be well visualized and never out of site or in deep tissue spaces. Category III procedures include abdominal surgery, general anesthesia, cardiothoracic surgery, open extensive head and neck surgery, neurosurgery, non-elective procedures in the emergency department, obstetric and gynecologic surgery except those enumerated in Category II, orthopedic procedures, extensive plastic surgery, transplant surgery, evaluation of violent patients who may bite, and any extensive surgical procedure lasting more than 3 hours. ${ }^{3}$

The risk to an HCW of acquiring HIV from an HIV positive patient following a blood borne exposure from a single needle stick injury is about $\mathbf{0 . 3 \%}$. If an HIV positive surgeon who is not on antiretrovirals operates on a patient and the surgeon injures himself during the procedure, the risk of transmission is on the order of 2 to 24 out of $\mathbf{1 , 0 0 0 , 0 0 0}$. 3,9 If the surgeon is on antiretrovirals, extrapolating data from HPTN 0521, the risk goes down further by $96 \% .^{10}$ The Society for Healthcare Epidemiology recommends that no restrictions be placed on HCWs who perform Category 1 and Category 2 procedures, regardless of viral load. For Category 3 procedures, significant viral suppression is required to minimize risk to the patient, on the order of $<500$ viral copies $/ \mathrm{mL}^{3}$

Caveats to continuing practice at every level of risk is that hospital management is aware of the HCW's status. A system of monitoring compliance needs to be in place, and the HIV-positive HCW needs to be under the care of a competent physician skilled in managing HIV. While SHEA ${ }^{3}$ requires specific contracts to be drawn up between the affected HCW and a hospital infection control team, this requirement can be tailored depending on the preference of each institution's policy. There is no need to reveal to the patient the status of the HCW since the consequent stigma associated with revealing an affected HCW's identity far outweighs the actual risk, especially if the HCW is already on antiretrovirals and is virally suppressed.

\section{Responsiblities of the affected HCW}

HCWs with HIV, if they wish to continue practice, need to commit themselves to minimizing risks to patients. They have to be highly compliant with medications, have regular follow-up every 3 months with their HIV healthcare provider, and use double gloves during exposure prone procedures. HIV viral load needs to be checked at a minimum of every six months, and needs to be under 500 copies $/ \mathrm{mL}$ in order to safely perform Category III procedures. ${ }^{3}$

In the event of a possible exposure during the procedure (e.g., nicking one's hand with a scalpel during surgery), the affected HCW must immediately withdraw from the procedure and have a replacement to take over the surgery. The patient should be informed that an exposure occurred as soon as possible, and offered prophylactic antiretrovirals, preferably within hours of the exposure, and serial testing. There is no need to reveal the affected HCW's identity to the patient, only the fact that the exposure occurred. ${ }^{3}$

As a corollary, the hospitals that may allow practice of HIV-positive HCWs should have an HIV-AIDS Core Team (HACT) in place as required by law (Republic Act 8504), and should have access to antiretrovirals from the nearest treatment hub, so that any exposed patient can be started on antiretrovirals as soon as possible, at the very least within 48-72 hours of exposure. ${ }^{9}$ The HACT, along with the hospital infection control unit is responsible for monitoring the HCWs compliance with whatever precautions are agreed upon, and to disclose to the patient in the event of an exposure. Recommended ARV regimens for post-exposure prophylaxis should include a protease inhibitor, specifically lopinavir-ritonavir two tablets twice a day and a two-NRTI backbone, preferably tenofovir and lamivudine. The rationale for a three-drug regimen inclusive of lopinavirritonavir is that the index case (the HCW) is presumably on antiretrovirals and therefore there is a theoretical risk of transmitted drug resistance. The length of treatment should be as recommended by current guidelines, typically 28 days. ${ }^{9}$ The exposed patient should be tested for HIV at baseline, one month, three months, and six months after the exposure. 
In HCWs who are diagnosed with HIV with very low CD4 counts $(<50$ cells $/ \mu \mathrm{L})$, the risk of acquiring opportunistic infections is substantially increased especially for those who are in highly stressful environments with long work hours, and in those who take care of patients with infectious diseases, particularly those infected with tuberculosis. We recommend that HCWs in these environments request a transfer to less stressful and infectious setting at least until substantial immune-reconstitution has occurred (CD4 count $>200$ cells $/ \mu \mathrm{L}$ ). Coordination with hospital infection control and the health service should be done, and the HIV healthcare provider should clear the HCW prior to resumption of duties in highly stressful or infectious environments.

\section{Conclusion}

As a consequence of the unprecedented increase in Filipinos living with HIV, more and more HCWs are finding themselves infected with this disease. In order to minimize the impact of this disease on HCWs and their patients, a proper framework to continue practice is proposed, in line with evidence-based guidelines from SHEA. This will ensure fair treatment for HCWs living with HIV while minimizing safety issues for patients. Physician specialty societies, led by the Philippine Society for Microbiology and Infectious Diseases are currently in the process of formulating guidelines for nationwide dissemination. In the meantime, a prudent and nuanced approach to HCWs with HIV should be taken in order to maximize outcomes and mitigate risks.

\section{References}

1. Department of Health - Epidemiology Bureau. Philippine HIV and AIDS Registry August 2015. Department of Health, Republic of the Philippines. 2015.

2. Trinidad AC, Dionisio Jr. DO, Naldoza RS. The experiences of external and internal stigma of HIV positive Filipinos. Phil Pop Rev. 2011; 10:4363.

3. Henderson DK, Dembry L, Fishman NO, et al. SHEA guideline for management of healthcare workers who are infected with hepatitis B virus, hepatitis $C$ virus, and/or human immunodeficiency virus. Infect Control Hosp Epidemiol. 2010; 31(3):203-32.

4. Department of Health. The Management of HIV-infected Healthcare Workers Department of Health's Response to Consultation August 2013. United Kingdom gov.uk. 2013 [Online]. [Accessed 2015 Oct]. Available from https://www.gov.uk/government/uploads/system/uploads/ attachment_data/file/229784/HIV_infected_HCW_-

_Consultation_Response.pdf

5. Australian Health Practioner Regulation Agency. Public consultation: Guidelines for the management of registered health practitioners and students infected with blood-borne viruses July 2014. Commonwealth of Australia 2014 [Online]. [Accessed 2015 Oct]. Available from http://www.ahpra.gov.au/documents/default.aspx?record=WD14\%2f143 60\&dbid=AP\&chksum=Lhl6\%2bFrZNfpD95y7lHMnoQ\%3d\%3d.

6. INSIGHT START Study Group, Lundgren JD, Babiker AG, Gordin F, et al. Initiation of Antiretroviral Therapy in Early Asymptomatic HIV Infection. N Engl J Med. 2015; 373(9):795-807.

7. Cohen MS, Smith MK, Muessig KE, Hallett TB, Powers KA, Kashuba AD.Antiretroviral treatment of HIV-1 prevents transmission of HIV-1: where do we go from here? Lancet. 2013; 382(9903):1515-24.
8. Panel on Antiretroviral Guidelines for Adults and Adolescents. Guidelines for the use of antiretroviral agents in HIV-1-infected adults and adolescents. Department of Health and Human Services [Online]. [Accessed 2015 Oct]. Available from http://www.aidsinfo.nih.gov/ ContentFiles/Adultand AdolescentGL.pdf.

9. Kuhar DT, Henderson DK, Struble KA, et al. US Public Health Service Working Group. Updated US Public Health Service guidelines for the management of occupational exposures to human immunodeficiency virus and recommendations for postexposure prophylaxis. Infect Control Hosp Epidemiol. 2013; 34(9):875-92.

10. Cohen MS, Chen YQ, McCauley M, et al. Prevention of HIV-1 infection with early antiretroviral therapy. N Engl J Med. 2011; 365(6):493-505. 